\title{
Biochemical assessment of histochemical methods for oestrogen receptor localisation
}

\author{
JCE UNDERWOOD, ${ }^{*}$ E SHER, $\dagger$ M REED, ${ }^{*}$ JA EISMAN, $\dagger$ TJ MARTIN $\dagger$ \\ From the *Department of Pathology, University of Sheffield Medical School, Sheffield S1O 2RX, and the \\ $\dagger$ Department of Medicine, University of Melbourne, Repatriation General Hospital, Victoria 3077, \\ Australia
}

SUMMARY The biochemical validity of published labelled-ligand and ligand-antibody methods for the histological localisation of oestrogen receptors (ER) in breast carcinomas was assessed by measuring specific and non-specific binding of ${ }^{3} \mathrm{H}$-oestradiol to pretreated MCF-7 monolayers; the monolayers had been either frozen and thawed, then air-dried or acetone-fixed, or fixed in formaldehyde to reproduce the conditions in published methods. The results indicate that most of the ER in a frozen section is likely to be lost by diffusion into the supernatant incubation medium. Fixation substantially restricts diffusion but reduces specific oestradiol binding and may increase non-specific binding; acetone fixation is particularly deleterious. Preincubation in oestradiol fails to protect the receptor during fixation. We conclude that the published histochemical methods for ER localisation have doubtful validity and should not yet be used in preference to conventional biochemical assays.

Several methods have been proposed for the histological localisation of oestrogen receptors (ER) in breast cancer $;^{1-11}$ such methods have the potential advantages over conventional biochemical ER assays of allowing morphological assessment of tumour cell heterogeneity with respect to ER content, elimination of problems due to contamination of tumour homogenates by stromal elements, and enabling subcellular localisation of hormone binding and translocation. It is claimed that ER can be histologically demonstrated either by tracing bound oestradiol with a specific antibody by immunofluorescence or immunohistochemistry1-3 $5810-11$ or by using oestradiol prelabelled with a fluorescent or enzyme marker. 4 6-7 911

The development and evaluation of these histochemical techniques has been conducted at a purely morphological level and, while appropriate controls are sometimes included, the end result has to be subjectively interpreted. "Specific" binding of hormone to high affinity, low capacity receptors and "non-specific" binding to low affinity, high capacity hormone-binding substances may be impossible to distinguish in the one histological preparation. The use of unfixed frozen sections risks possible loss of receptor by diffusion and exposure of sections to histological fixatives ${ }^{511}$ raises further doubts about

Accepted for publication 27 August 1981 these techniques because of the known lability of the receptor in biochemical systems.

We have investigated the biochemical validity of these histochemical methods by quantitative analysis of the binding of tritium-labelled oestradiol to MCF-7 cells, an oestrogen-responsive human breast carcinoma cell line. ${ }^{12}$ MCF-7 cell cultures were pretreated to mimic the procedures described in published histological methods, after which specific and non-specific oestradiol binding was measured.

\section{Material and methods}

MCF-7 CELLS

MCF-7 cells were grown in HEPES-buffered RPMI 1640 medium containing $10 \%$ fetal calf serum. Subcultures were done by incubating at $37^{\circ} \mathrm{C}$ for $2 \mathrm{~min}$ with $0.0125 \%$ trypsin in $0.02 \%$ EDTA-saline followed by the addition of serum and washing in phosphate-buffered saline (PBS) (Oxoid). For the hormone-binding experiments detailed below the cells were subcultured into either plastic multiwell trays (well diameter $3.5 \mathrm{~cm}$ ) or glass Petri dishes (diameter $4.0 \mathrm{~cm}$ ) at a density of approximately $2 \times 10^{6}$ cells per well or dish; the latter were used for experiments in which cells were to be exposed to plastic solvents such as acetone or xylene. Hormonebinding experiments were done with the cell monolayers at confluence and after $24 \mathrm{~h}$ prior incubation 
in medium containing fetal calf serum extracted with dextran-coated charcoal to remove steroid hormones. ${ }^{13}$

\section{PRETREATMENT OF CULTURES}

The medium was aspirated from the multiwell trays or glass dishes. The attached cell monolayers were frozen by gently placing the multiwell trays or glass dishes on a bath of dry ice in ethanol and then thawed at room temperature to simulate the freeze/ thaw sequence in the preparation of frozen section. Frozen/thawed monolayers were either air-dried at $4^{\circ} \mathrm{C}$ for one hour or fixed in acetone ${ }^{11}$ for $4 \mathrm{~min}$ followed by washing in PBS. Unfrozen monolayers were fixed in neutral buffered $10 \%$ formalin for 15 min followed by washing in PBS. The alleged improved stability of ER produced by preincubating the fresh tissue with oestradiol before formalin fixation ${ }^{5}$ was assessed by incubating live MCF-7 cell monolayers in $7 \times 10^{6} M 17 \beta$-oestradiol in RPMI 1640 containing $0.05 \%$ bovine serum albumin (BSA) for $30 \mathrm{~min}$ at room temperature. After fixation in formalin for $15 \mathrm{~min}$ the monolayers were washed in three changes of PBS, dehydrated in ethanol, "cleared" in xylene, then rehydrated through ethanol to PBS. Control cultures in which the oestradiol preincubation was omitted were handled similarly.

\section{HORMONE BINDING}

MCF-7 monolayers, either live or pretreated as above, were incubated with $10^{-9} M[2,4,6,7,16$, 17- ${ }^{3} \mathrm{H}$ ]-oestradiol (154 Ci/mmol) (Radiochemical Centre, Amersham) in $0.05 \%$ BSA in PBS for one hour at room temperature. In some experiments Trasylol (Bayer) at $1000 \mathrm{u} / \mathrm{ml}, 25 \%$ polyethylene glycol 6000 (PEG) or $25 \%$ polyvinyl pyrrolidone (PVP) were included. The supernatant incubation mixture was then aspirated and treated as detailed below. The monolayers were gently washed in three changes of $0.2 \%$ BSA in PBS to remove free hormone, cells were dislodged with $1 M$ sodium hydroxide, neutralised with $1 M$ hydrochloric acid, and added to $7 \mathrm{ml}$ of Handifluor (Scintillar) or Instagel (Packard) scintillant. Non-specific binding was determined in replicate monolayers incubated with $10^{-9} M$ tritiated oestradiol in the presence of $10^{-6} M$ diethylstilboestrol. All determinations were done in triplicate.

\section{TREATMENT OF SUPERNATANTS}

Possible diffusion of hormone-binding substances during incubation was investigated by mixing $1 \mathrm{ml}$ supernatant with $200 \mu \mathrm{l}$ of dextran-coated charcoal $(0.1 \%$ dextran $\mathrm{T}-70$ and $1 \%$ charcoal $)$ to remove free hormone. After centrifugation at $2500 \mathrm{rpm}$ for 10 min at $4^{\circ} \mathrm{C}$ the supernatant was added to $10 \mathrm{ml}$ of
Handifluor or Instagel scintillant.

Specific oestradiol binding to cell monolayers and in supernatants was calculated by subtraction of the non-specific ${ }^{3} \mathrm{H}$-oestradiol binding (in the presence of $10^{-6} M \mathrm{DES}$ ) from the total maximum binding (in the absence of $10^{-6} M$ DES).

\section{Results}

OESTRADIOL UPTAKE BY MCF-7 MONOLAYERS The uptake of tritiated oestradiol by living MCF-7 monolayers was studied over a two-hour period. Specific oestradiol binding reaches its peak value after approximately one hour, though non-specific binding (in the presence of DES) continues to rise after this time (Fig. 1).

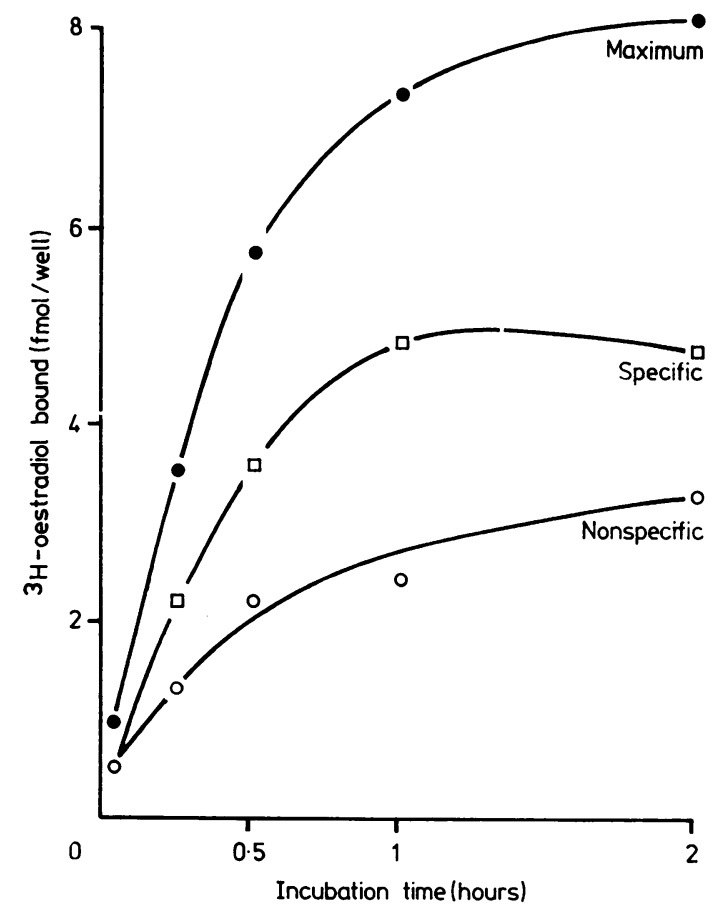

Fig. 1 Uptake of ${ }^{3} \mathrm{H}$-oestradiol $\left(10^{-9} \mathrm{M}\right)$ by MCF-7 cells in culture. Non-specific uptake is in the presence of diethylstilboestrol $\left(10^{-6} \mathrm{M}\right)$. The curve for specific binding, attributable to a high affinity oestrogen receptor, is derived by subtraction of the non-specific binding from the maximum binding at each time point.

FROZEN AND THAWED MCF-7 MONOLAYERS In typical experiments the amount of specific oestradiol binding to air-dried frozen/thawed MCF-7 monolayers was approximately $10 \%$ of the specific binding attainable in replicate cultures of live cells (Fig. 2). Analysis of the supernatant medium from the hormone incubations, by the dextran-coated 
charcoal method, demonstrated that a considerable amount of the specific oestradiol binding activity had diffused out of the monolayers (Table). Inclusion of polymeric stabilisers, either PVP or PEG, in the incubation medium improved the final morphological appearance of the monolayers but did not result in any detectable reduction in receptor diffusion. Diffusion of binding activity was also unaffected by inclusion of Trasylol $(1000 \mathrm{u} / \mathrm{ml})$ in the incubation medium.

Recovery of oestrogen receptor from frozen and thawed and fixed MCF-7 monolayers after incubation for one hour with $10^{-9} \mathrm{M}^{3} \mathrm{H}$-oestradiol

\begin{tabular}{llll}
\hline Monolayer status & \multicolumn{2}{l}{ Recovery } & \\
\cline { 2 - 4 } & $\begin{array}{l}\text { Monolayer } \\
\%\end{array}$ & $\begin{array}{l}\text { Supernatant } \\
\%\end{array}$ & $\begin{array}{l}\text { Unrecovered } \\
\%\end{array}$ \\
\hline Live & 100 & 0 & 0 \\
Frozen/thawed & 12 & 70 & 18 \\
Frozen/thawed/ & $1 \cdot 1$ & 0 & 98.9 \\
Focetone-fixed & 29 & $1 \cdot 1$ & 69.9 \\
\hline
\end{tabular}

\section{ACETONE FIXATION}

Acetone fixation of frozen/thawed MCF-7 monolayers totally eliminated detectable diffusion of receptors into the incubation medium (Table); specific oestradiol binding to the monolayers was, however, reduced to negligible proportions, approximately $1 \%$ of that attainable in replicate live cells (Fig. 2). Non-specific binding was unaffected.

\section{FORMALIN FIXATION}

As with acetone fixation. formalin substantially reduced the tendency of receptor to diffuse into the supernatant (Table). This was accompanied by significant reduction in specific oestradiol binding to the monolayers and doubling of non-specific binding (Fig. 2).

\section{FORMALIN FIXATION OF OESTRADIOL-}

PRETREATED MONOLAYERS

Exposure of formalin-fixed cells prelabelled with tritiated oestradiol to ethanol reduced the oestradiol content, both specifically and non-specifically bound, to negligible proportions (Fig. 3). However, reincubation of such cells with tritiated oestradiol, with and without an excess of DES, failed to demonstrate any detectable protection of the receptor during formalin fixation; the degree of specific and non-specific binding was similar to that seen in replicate cultures fixed in formalin and exposed to ethanol but without preincubation in oestradiol (Fig. 3).

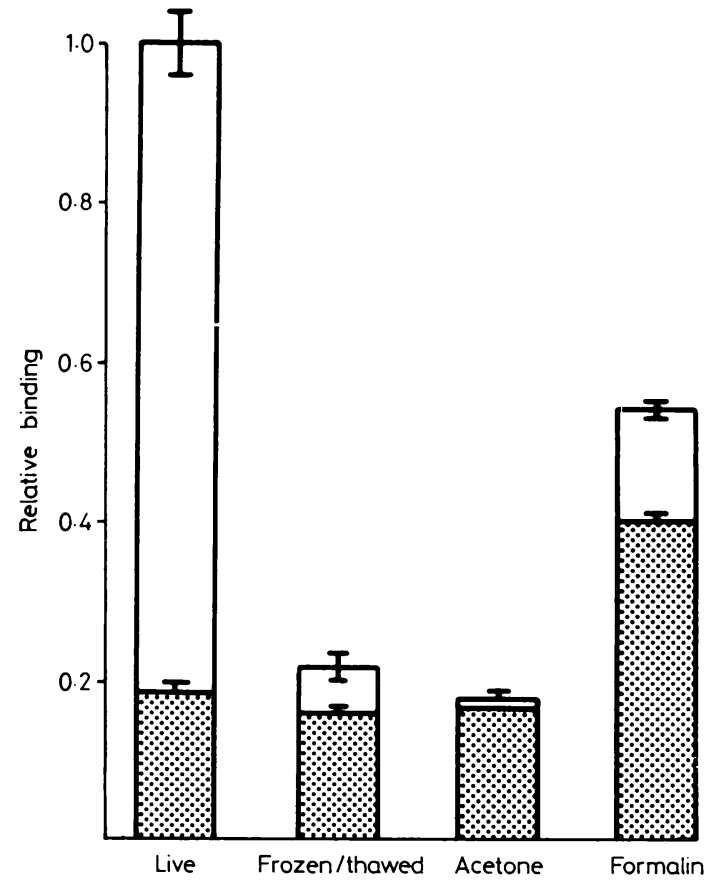

Fig. 2 Binding of ${ }^{3} \mathrm{H}$-oestradiol $\left(10^{-9} \mathrm{M}\right)$ to live $\mathrm{MCF}-7$ monolayers, frozen and thawed monolayers, formalin-fixed monolayers and acetone-fixed monolayers. Difference between total maximum binding and non-specific binding (stippled) indicates specific binding attributable to receptor (bars denote $S E M$ ).
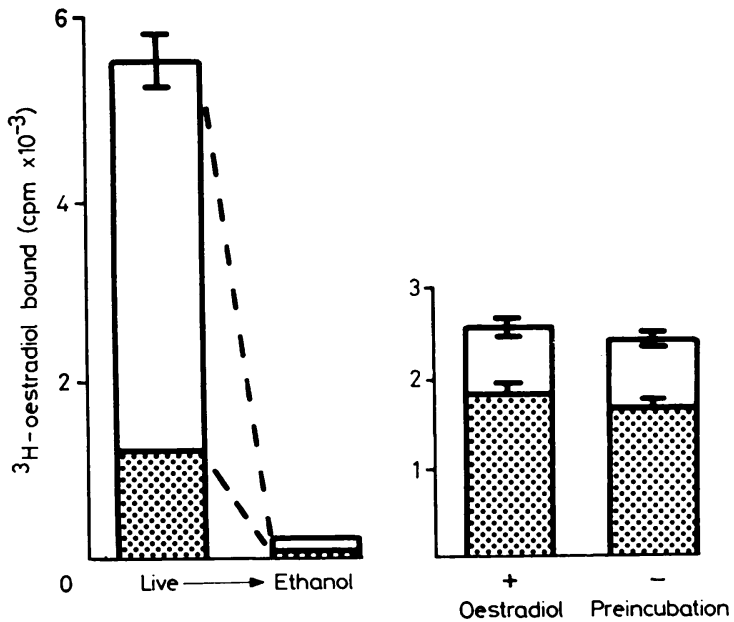

Fig. 3 (Left) Elution of specifically and non-specifically bound (stippled) ${ }^{3} \mathrm{H}$-oestradiol from prelabelled formalinfixed MCF-7 monolayers on exposure to ethanol. (Right) Failure of oestradiol preincubation to protect receptor during formalin fixation; ${ }^{3} \mathrm{H}$-oestradiol $\left(10^{-9} \mathrm{M}\right)$ binding is not significantly different from that attained in replicate monolayers not preincubated in oestradiol prior to formalin fixation and ethanol treatment. 


\section{Discussion}

The assay of specific steroid hormone receptors, as characterised by biochemical criteria, in breast cancers can have therapeutic implications for individual patients. Conventional assays are done on tissue homogenates; there the information derived is quantitative but conveys no information about the possible heterogeneity of the tumour cell population; a "receptor-positive" tumour may contain numerous receptor-negative tumour cells. Tumour homogenates may also be contaminated by stromal constituents, resulting in either dilution of the receptor derived from the neoplastic cells or enrichment of the homogenate with receptor from connective tissue cells. These inherent disadvantages of the biochemical assays have motivated the development of morphological methods based on histochemistry from which the receptor content of individual cells may be deduced.

From this study employing biochemical criteria it is clear that none of the published histochemical methods for oestrogen receptor localisation is satisfactory. Our results demonstrate that the use of unfixed frozen sections for such methods ${ }^{2-4}$ 6-10 is unsatisfactory because of the facility with which the receptor diffuses into the supernatant during incubation with hormone. Our attempts to minimise receptor diffusion by including a limited range of polymeric tissue stabilisers ${ }^{14}$ in the incubation medium have met with little success other than to improve substantially the final morphological result and to improve agreement between replicates. Trasylol, a protease inhibitor, also failed to increase the amount of receptor recoverable from frozen and thawed monolayers.

It could be argued that cultured cell monolayers are not strictly analagous to tissue sections. We would regard the monolayer, however, as representing the more favourable situation in which to retain diffusible substances in frozen and thawed cells; in conventional frozen sections many cells are transected thus permitting unrestricted diffusion into the supernatant, whereas the cells in a frozen and thawed monolayer are still bounded by a membrane (albeit one that has sustained the damage associated with freezing).

Kurzon and Sternberger claim that oestrogen receptor will withstand the potential rigours of formalin fixation if the fresh tissue or cells are first incubated in unlabelled oestradiol. ${ }^{5}$ Their contention that passage of the tissue through ethanol during processing will remove oestradiol previously bound to the receptors is supported by the results in this paper. There is, however, evidence from the results presented here that this preliminary hormone in- cubation before fixation does not afford any measure of protection. Formalin does restrict the tendency of the receptor to diffuse and does preserve a measurable degree of specific binding within the cells, though at cost of a significant increase in nonspecific binding.

Acetone fixation almost totally abolishes specific binding and would appear to be the least effective method for fixing tissue sections or cells for receptor localisation. ${ }^{11}$ Presumably the receptor is denatured and its conformation altered in such a way that it can no longer bind hormone. Unlike formalin, however, acetone fixation does not lead to any enhancement of non-specific binding activity in the cells.

In summary, our findings indicate that most of the oestradiol bound to air-dried or fixed cells or sections is likely to be associated with low affinity nonspecific binding substances rather than a high affinity oestrogen receptor. It is difficult, therefore, to accept the conclusion that such methods are valid for the histochemical demonstration of ER.

Further doubts about the published histochemical methods for ER localisation have been raised. There are theoretical objections to the ligand-antibody method;1-3 $5810-11$ oestradiol bound to ER appears to be inaccessible to oestradiol antibodies, because the receptor-hormone interaction is of clathrate type (see legend, Fig. 4), ${ }^{15-17}$ and consequently any oestradiol traced by immunofluorescence or immunohistochemistry is more likely to be nonspecifically bound (Fig. 4). There are also objections to the validity of the labelled-ligand method; fluorescein-conjugated oestradiols ${ }^{469}$ have low relative binding affinities for $\mathrm{ER}^{18}$ (the same may be true of peroxidase-conjugated hormone) and competition studies for ${ }^{3} \mathrm{H}$-oestradiol binding may be invalidated by contamination of the fluorescein conjugated preparation with free oestradiol. ${ }^{19} 20$ In both methods the oestradiol concentration employed is invariably in excess of that necessary to achieve saturation of the classical high affinity type I oestrogen receptor and probably results in oestradiol binding to low affinity oestrogen binding sites, designated types II and III. ${ }^{19}$ The clinical and therapeutic significance of these binding sites in breast carcinomas awaits elucidation.

More work is clearly necessary to devise a method compatible with morphological and biochemical considerations. Theoretical objections to both the antioestradiol antibody method and the labelled oestradiol method may, however, serve to motivate the development and use of specific antibodies (for example, monoclonal) to oestrogen and other hormone receptors. ${ }^{21}$ 


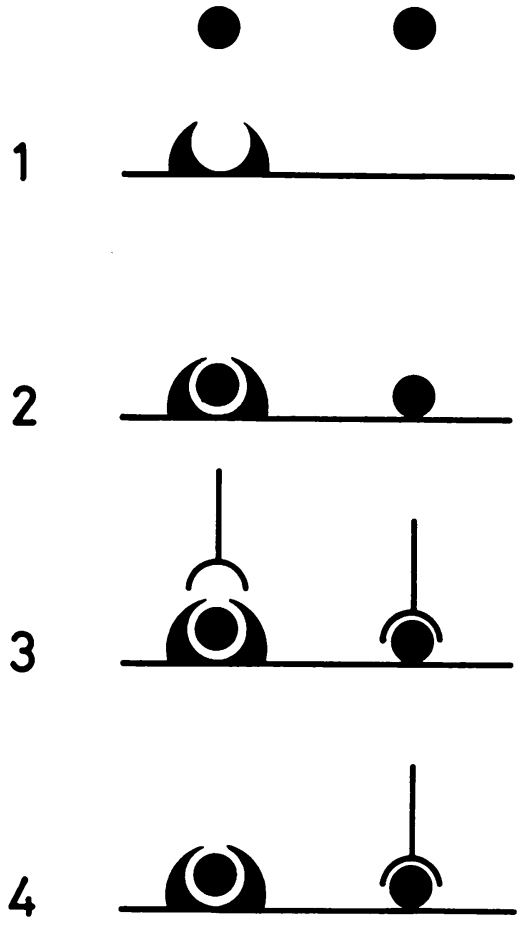

Fig. 4 Hypothetical mode of interaction between oestradiol and its high affinity receptor (left) or a nonspecific binding site (right) and subsequent tracing by antioestradiol antibody: 1 oestradiol (solid circles) added to tissue section; 2 high affinity receptor binds and encloses oestradiol, an interaction described as clathrate (from the Latin word "clathrare" meaning to furnish with a lattice or bars); 3 oestradiol sequestered within receptor is relatively inaccessible to added antioestradiol antibody unless receptor opens; 4 after washing, only the antibody associated with non-specifically bound oestradiol remains adherent to the section.

JCEU was in receipt of a Wellcome-Ramaciotti Research Travel Grant. Support of the Anti-Cancer Council of Victoria and the National Health and Medical Research Council of Australia is acknowledged. Sharyn Omond provided excellent technical assistance.

\section{Addendum}

After this paper was submitted for publication Taylor $e t a^{22}$ reported putative oestrogen receptor detection by the immunoperoxidase technique using polyoestradiol phosphate ligand with paraffin sections of formalin-fixed breast and endometrial carcinomas. This method is subject to the general criticism of the ligand-antibody techniques and the specific problems consequent upon formalin fixation. Indeed the authors concede that their technique may not be detecting the same high affinity receptor that is measured by conventional cytosol-based assays.

\section{References}

1 Nenci I, Beccati MD, Piffanelli A, Lanza G. Detection and dynamic localisation of oestradiol-receptor complexes in intact target cells by immunofluorescence. $J$ Steroid Biochem 1976;7:505-10.

2 Pertschuk LP. Detection of oestrogen binding in human mammary carcinoma by immunofluorescence: a new technique utilising the binding hormone in a polymerised state. Res Commun Chem Pathol Pharmacol 1976;14: 771-4.

${ }^{3}$ Pertschuk LP, Tobin EH, Brigati DJ, et al. Immunofluorescent detection of oestrogen receptors in breast cancer: comparison with dextran-coated charcoal and sucrose gradient assays. Cancer 1978;41:907-11.

4 Pertschuk LP, Gaetjens E, Carter AC, Brigati DJ, Kim DS, Fealey TE. An improved histochemical assay for detection of oestrogen receptors in mammary cancer: comparison with biochemical assay. Am J Clin Pathol 1979;71:504-8.

${ }^{5}$ Kurzon RM, Sternberger LA. Oestrogen receptor immunocytochemistry. J Histochem Cytochem 1978;26:803-8.

- Dandliker WB, Brawn RJ, Hsu M-L, et al. Investigation of hormone-receptor interactions by means of fluorescence labelling. Cancer Res 1978;38:4214-24.

7 Rao BR, Fry CG, Hunt S, Kuhnel R, Dandliker WB. A fluorescent probe for rapid detection of oestrogen receptors. Cancer 1980;46:2902-6

${ }^{8}$ Ghosh L, Ghosh BC, DasGupta TK. Immunocytological localisation of oestrogen in human mammary carcinoma cells by horseradish-anti-horseradish peroxidase complex. J Surg Oncol 1978;10:221-4.

${ }^{9}$ Lee SH. Cytochemical study of oestrogen receptor in human mammary cancer. Am J Clin Pathol 1978;70: 197-203.

${ }^{10}$ Mercer WD, Lippman ME, Wahl TM, et al. The use of immunocytochemical techniques for the detection of steroid hormones in breast cancer cells. Cancer 1980;46: 2859-68.

11 Walker RA, Cove DH, Howell A. Histological detection of oestrogen receptors in human breast carcinomas. Lancet 1980; 1 :171-3.

12 Horwitz KB, Costlow ME, McGuire WL. MCF-7: a human breast cancer cell line with oestrogen, androgen, progesterone and glucocorticoid receptors. Steroids 1975;26:785-95.

${ }^{13}$ Lippman ME, Bolan D. Oestrogen-responsive human breast cancer in long term tissue culture. Nature 1975; 256:592-3.

${ }^{14}$ Altman FP. Tissue stabiliser methods in histochemistry. In: Evered D, O'Connor M, eds. Trends in enzyme histochemistry and cytochemistry. Ciba Foundation Symposium, 1980;73:81-102.

${ }^{15}$ Castaneda E, Liao S. The use of antisteroid antibodies in the characterisation of steroid receptors. J Biol Chem 1975;250:883-902.

${ }^{16}$ Fishman J, Fishman JH, Nisselbaum JS, et al. Measurement of the oestradiol receptor in human breast tissue by the immobilised antibody method. J Clin Endocrinol Metab 1975;40:724-7.

17 Morrow B, Leav I, DeLellis RA, Raam S. Use of polyestradiol phosphate and anti-17 $\beta$-oestradiol antibodies for the localisation of oestrogen receptors in target tissues: a critique. Cancer 1980;46:2872-9.

18 McCarty KS, Woodard BH, Nichols DE, Wilkinson W, McCarty KS Snr. Comparison of biochemical and 
histochemical techniques for oestrogen receptor analyses in mümmary carcinoma. Cancer 1980;46:2842-5.

${ }^{19}$ Chamness GC, Mercer WD, McGuire WL. Are histochemical methods for oestrogen receptor valid? $J$ Histochem Cytochem 1980;28:792-8.

20 Barrows GH, Stroupe SB, Riehm JD. Nuclear uptake of a $17 \beta$-oestradiol fluorescein derivative as a marker of oestrogen dependence. Am J Clin Pathol 1980;73:330-9.

${ }^{21}$ Greene GL, Nolan C, Engler JP, Jensen EV. Monoclonal antibodies to human oestrogen receptor. Proc Natl Acad
Sci USA 1980;77:5115-9.

${ }^{22}$ Taylor CR, Cooper CL, Kurman RJ, Goebelsmann U, Markland FS. Detection of oestrogen receptor in breast and endometrial carcinoma by the immunoperoxidase technique. Cancer 1981;47:2634-40.

Requests for reprints to: Dr JCE Underwood, Department of Pathology, University of Sheffield Medical School, Beech Hill Road, Sheffield S10 2RX, England. 